\title{
Reactivity of functionalized thiosemicarbazone complexes towards phosphines ${ }^{\dagger}$
}

\author{
Francisco Reigosa 1,*, Fátima Lucio 1, Paula Munín 1, Pablo Frieiro 1, Adolfo Fernández 1, \\ $M^{a}$ Teresa Pereira ${ }^{1}$ and José Manuel Vila ${ }^{1}$. \\ 1 Department of Inorganic Chemistry, Faculty of Chemistry University of Santiago de Compostela, Avd. Das \\ Ciencias, s/n, 15782 Santiago de Compostela, Spain; francisco.reigosa@usc.es; \\ fatimaluciomartinez@gmail.com; paula.munin@usc.es; pablojuan.frieiro@gmail.com; \\ adolfo_esteiro@hotmail.com; mteresa.pereira@usc.es; josemanuel.vila@usc.es \\ * francisco.reigosa@usc.es; Tel.: +34-881 814442 \\ + Presented at the 21st International Electronic Conference on Synthetic Organic Chemistry, 1-30 November \\ 2017.
}

Academic Editor: name

Received: date; Accepted: date; Published: date

\begin{abstract}
Herein we report the design, synthesis and characterization of a series of phenylboronic cyclometallated derivatives bearing different phosphines. The compounds were prepared by reaction of cyclometallated species with different phosphine ligands and they were characterized by IR, ${ }^{1} \mathrm{H}$ and ${ }^{31} \mathrm{P}$ NMR spectroscopy.
\end{abstract}

Keywords: Boronic Acid, Catalysis, Suzuki, Thiosemicarbazone, Palladium, Characterization

\section{Introduction}

Thiosemicarbazones are versatile ligands which are able to coordinate to metals through $\mathrm{C}, \mathrm{N}$ and $\mathrm{S}$ atoms. When bonding to the metal is through the sulfur, iminic nitrogen and a carbon atoms cyclometallated compounds are formed. These have aroused great interest due to their wide range of applications. Their biological activity depends on the parent aldehyde or ketone [1-3]; also, palladium (II) complexes have proved to be useful as catalysts in cross coupling reactions like the Heck and Suzuki-Miyaura cross-coupling reaction [4-7].

Previous studies have shown the tetranuclear structure of these compounds [8, 9], which implies a low solubility in the common organic solvents, limiting their potential applications. For this reason we pursue tetranuclear compounds with better solution properties by using different organic precursors; in this particular case an organic precursor bearing the boronic acid functionality. The boronic acid could lead to further modification of the structure of the cyclometallated tetranuclear compound using the Suzuki cross-coupling reaction. Reactivity towards phosphine ligands provides different structures [10] that modulate the applicability to the coupling reaction.

Herein we report the synthesis of a series of cyclometallated compounds derived from a boronic thiosemicarbazone.

\section{Methods}

The ligands were prepared by the condensation of acetylphenylboronic acid with different thiosemicarbazides (Figure 1). Acetylphenylboronic acid and hydrochloric acid (35\%) were added to a suspension of the corresponding thiosemicarbazide in water $\left(25 \mathrm{~cm}^{3}\right)$ to give a clear solution, which was stirred at room temperature for $4 \mathrm{~h}$. The white solid that precipitated was filtered off, washed with cold water and dried in air. 


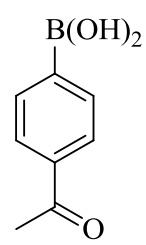<smiles>[R]NC(=S)NN</smiles>

$\mathrm{R}=\mathrm{H}, \mathrm{Me}, \mathrm{Et}$<smiles>[R17]NC(=S)N/N=C(\C)c1ccc([R16]([H])([H])[H])cc1</smiles>

L1 R=H

L2 $\mathrm{R}=\mathrm{Me}$

Figure 1.

The palladium compounds were prepared by the addition of a solution of $\mathrm{K}_{2}\left[\mathrm{PdCl}_{4}\right]$ in water to an ethanolic solution of the ligand, as appropriate (Figure 2). The reaction mixture was then kept at room temperature for $24 \mathrm{~h}$. The precipitated yellow solids were filtered, redissolved in DCM and filtered. The solvent was removed to yield compounds in $78-88 \%$ yield.

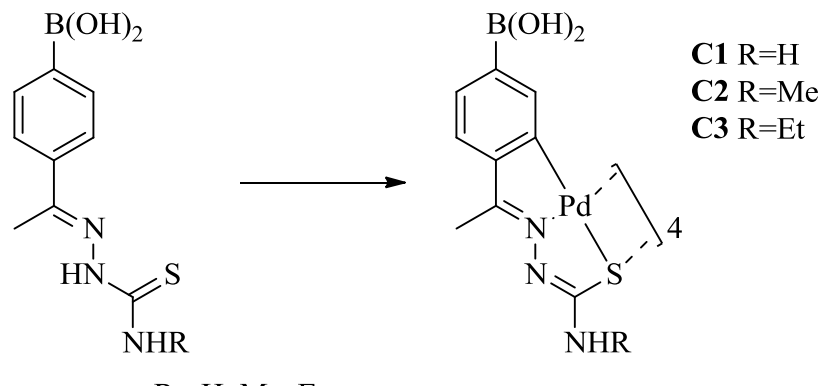

$\mathrm{R}=\mathrm{H}, \mathrm{Me}, \mathrm{Et}$

Figure 2.

The synthesis of the phosphine derivatives was achieved by reaction of the palladacycles with the corresponding phosphine in the appropriate stoichiometric ratio. These reactions were carried out in oxygen-free acetone, under nitrogen at room temperature. After 5 hours, the solvent was removed under vacuum to give the target compounds (70-85\% yield). The phosphines used in this work were triphenylphosphine, dppm and dppb (Figure 3).

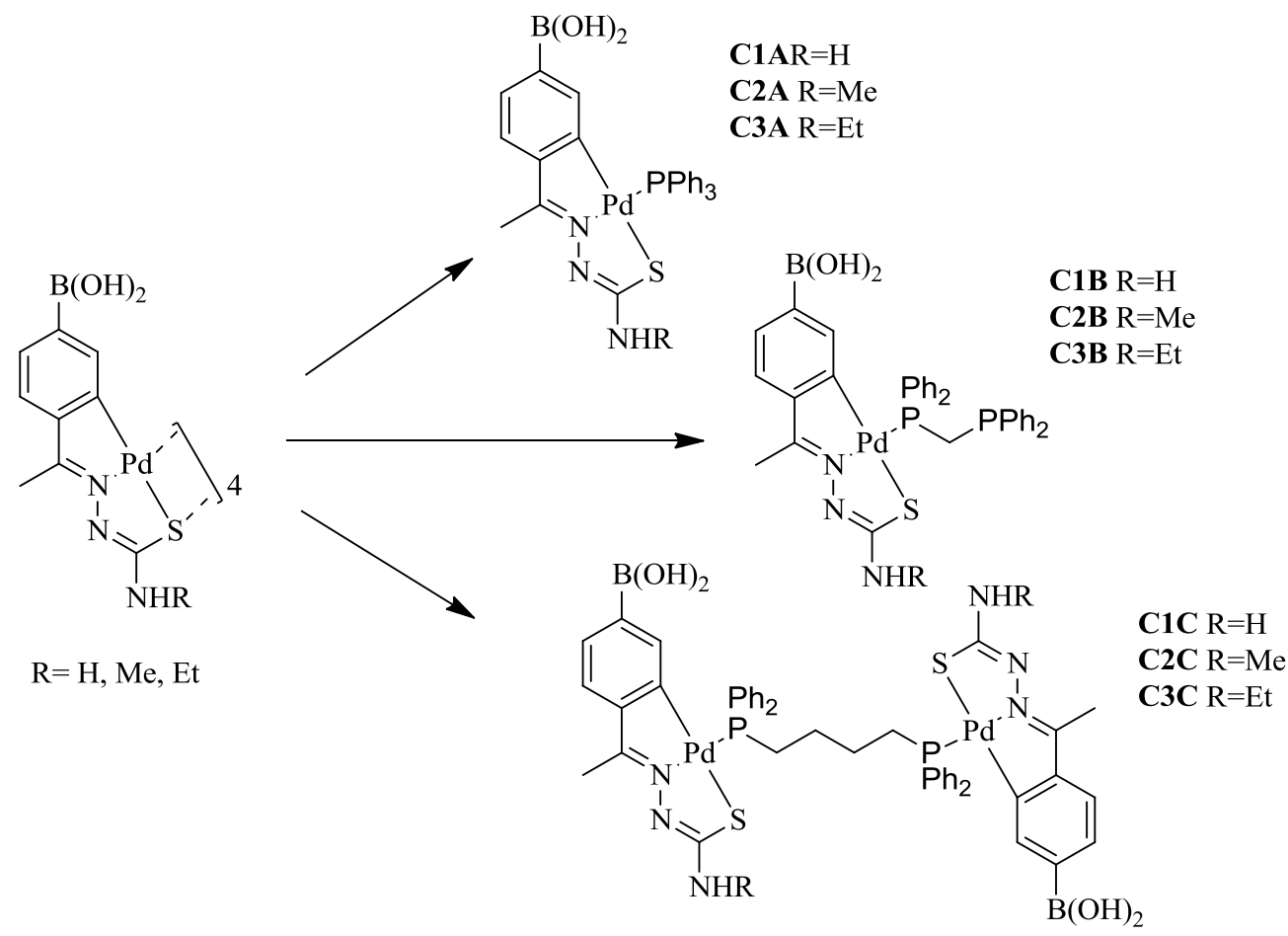

Figure 3. 
All the ligands and compounds were characterized by elemental analysis, IR spectroscopy, ${ }^{1} \mathrm{H}-\mathrm{NMR}$ and, in the case of the phosphine bearing compounds, ${ }^{31} \mathrm{P}-\left\{{ }^{1} \mathrm{H}\right\}-\mathrm{NMR}$.

\section{Results and discussion}

Ligands were obtained by the condensation of acetylphenylboronic acid with different thiosemicarbazides. Elemental analysis data matched the expected results and the ligands were characterized by ${ }^{1} \mathrm{H}-\mathrm{NMR}$ and IR.

The comparison of the ${ }^{1} \mathrm{H}-\mathrm{NMR}$ of the ligand and their corresponding compounds made clear the metalation of the phenyl ring (figure 1). In the spectra of the ligands a singlet ca. $10.2 \mathrm{ppm}$ was assigned to the hydrazinic proton and an $\mathrm{AA}^{\prime} \mathrm{BB}^{\prime}$ system $c a .7 .75 \mathrm{ppm}$ to the phenyl protons $(4 \mathrm{H})$.
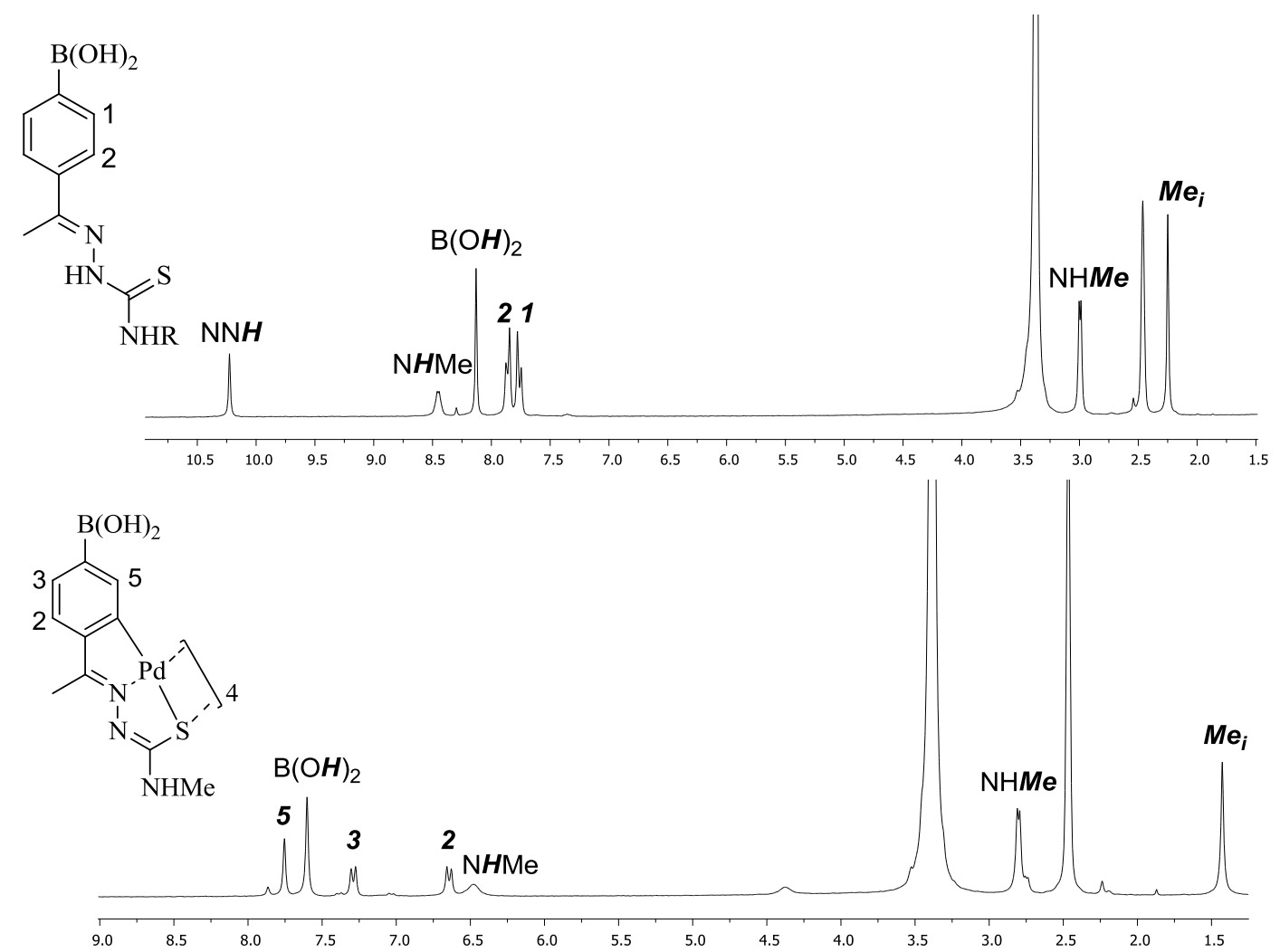

Figure 4. ${ }^{1} \mathrm{H}-\mathrm{NMR}$ of ligand $\mathrm{L} 2$ (top) and its corresponding metallated compound C2 (bottom), showing the changes in the aromatic region and the absence of the hydrazinic proton in the palladacycles.

The IR spectra of the ligands showed bands for the $\mathrm{C}=\mathrm{S}$ group and hydrazinic $\mathrm{v}(\mathrm{N}-\mathrm{H})$ stretch, which are absent in the spectra of the compounds (Table 2), confirming deprotonation of the thiosemicarbazone and the coordination in the thiolic form.

The shift of the $v(\mathrm{C}=\mathrm{N})$ band implies coordination is through the nitrogen lone pair and not through the $\mathrm{C}=\mathrm{N}$ double bond.

Table 1. IR data of the ligands and compounds.

\begin{tabular}{ccccccc}
\hline Compound & $v(\mathrm{C}=\mathrm{N})$ & $\Delta(\mathrm{C}=\mathrm{N})$ & $v(\mathrm{C}=\mathrm{S})$ & $v(\mathrm{~N}-\mathrm{H})$ & $v(\mathrm{~B}-\mathrm{O})$ & $v(\mathrm{O}-\mathrm{H})$ \\
\hline L1 & 1595 & - & 831 & 3314,3341 & 1363 & 3500 \\
C1 & 1578 & 17 & - & 3256 & 1382 & 3446 \\
L2 & 1592 & - & 819 & 3317,3321 & 1357 & 3450 \\
C2 & 1577 & 15 & - & 3341 & 1345 & 3427 \\
L3 & 1596 & - & 813 & 3272,3330 & 1352 & 3458 \\
C3 & 1570 & 26 & - & 3354 & 1350 & 3437 \\
\hline
\end{tabular}


Then, the reactivity towards different phosphine ligands was studied.

Due to their tetranuclear structure, the cyclometallated compounds present two types of Pd-S bonds, Metal-Schelate and Metal-Sbridging. The latter is weaker and the coordination of the phosphine ligands occurs at this position (Figure 5).

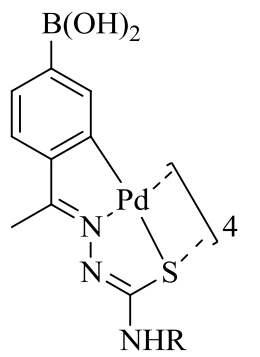

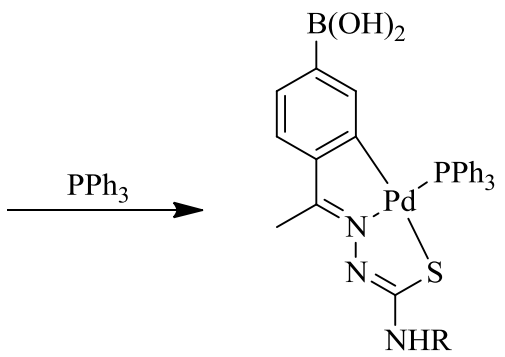

Figure 5. Reactivity of a palladacycle towards triphenylphosphine

The reaction of the cyclometallated compounds with triphenylphosphine gave the expected products. The ${ }^{1} \mathrm{H}-\mathrm{NMR}$ spectra of these compounds showed multiplets in the aromatic region corresponding to the protons of the phenyl rings. The multiplicity of the aromatic protons of the compounds is preserved, but there are changes in the shift of these signals, due to the proximity of the phenyl groups of the phosphine (Figure 6).

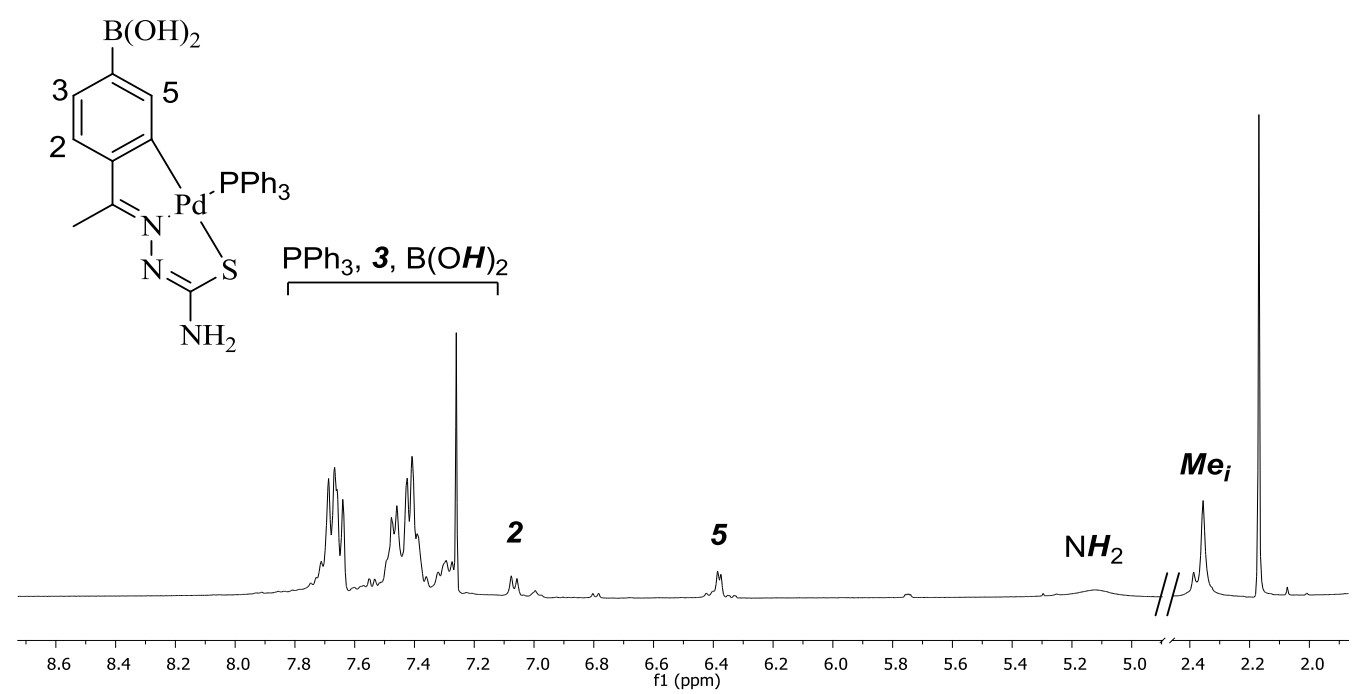

Figure 6. ${ }^{1} \mathrm{H}-\mathrm{NMR}$ spectrum of $\mathrm{C} 1 \mathrm{~A}$

The ${ }^{31}$ P-NMR spectra was a single singlet signal ca. 36 ppm (Figure 7, Table 2).

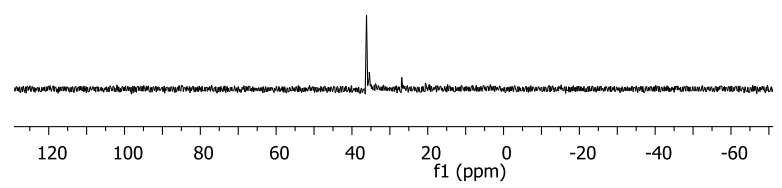

Figure 7. ${ }^{31} \mathrm{P}-\mathrm{NMR}$ spectrum of C1A

Table 2. ${ }^{31} \mathrm{P}-\mathrm{NMR}$ data for the triphenylphosphine derivatives.

\begin{tabular}{cccc}
\hline Signal & C1A / $\delta(\mathrm{ppm})$ & C2A / $\delta(\mathrm{ppm})$ & C3A / $(\mathrm{ppm})$ \\
\hline $\mathrm{Pd}-P \mathrm{Ph}_{3}$ & $36.16(\mathrm{~s})$ & $36.21(\mathrm{~s})$ & $35.33(\mathrm{~s})$ \\
\hline
\end{tabular}


In the compounds with dppm the ${ }^{1} \mathrm{H}-\mathrm{NMR}$ spectra was very similar to the previous case, with multiplets in the aromatic region and shift of the metallated ring resonances. A signal ca. $3.5 \mathrm{ppm}$ was assigned to the $\mathrm{CH}_{2}$ protons of the diphosphine. The ${ }^{31} \mathrm{P}-\mathrm{NMR}$ spectra confirms that the dppm ligand is monodentate, showing two doublets for ${ }^{31} \mathrm{P}$ nuclei.(Figure 8, Table 3).

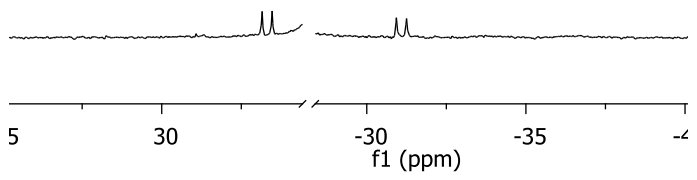

Figure 8. ${ }^{31} \mathrm{P}-\mathrm{NMR}$ spectrum of $\mathrm{C} 3 \mathrm{~B}$

Table 3. ${ }^{31} \mathrm{P}-\mathrm{NMR}$ data for the dppm derivatives.

\begin{tabular}{cccc}
\hline Signal & C1B / $\delta(\mathrm{ppm})$ & C2B $/ \delta(\mathrm{ppm})$ & C3B / $(\mathrm{ppm})$ \\
\hline $\mathrm{Pd}-P \mathrm{Ph}_{2}$ & $23.77(\mathrm{~d})$ & $24.46(\mathrm{~d})$ & $26.69(\mathrm{~d})$ \\
$P \mathrm{Ph}_{2}$ & $-27.15(\mathrm{~d})$ & $-27.06(\mathrm{~d})$ & $-31.09(\mathrm{~d})$ \\
\hline${ }^{2}(\mathrm{PP}) /(\mathrm{Hz})$ & 71.0 & 70.0 & 51.1 \\
\hline
\end{tabular}

The compounds with dppb are dinuclear, with the phosphine ligand acting in the bridging mode between the two moieties. Their ${ }^{1} \mathrm{H}-\mathrm{NMR}$ spectra, as in the previous cases, showed multiplet signals in the aromatic region. The signals of the diphosphine carbon chain appear as multiplets at 2.4 and 1.7 ppm (Figure 9).

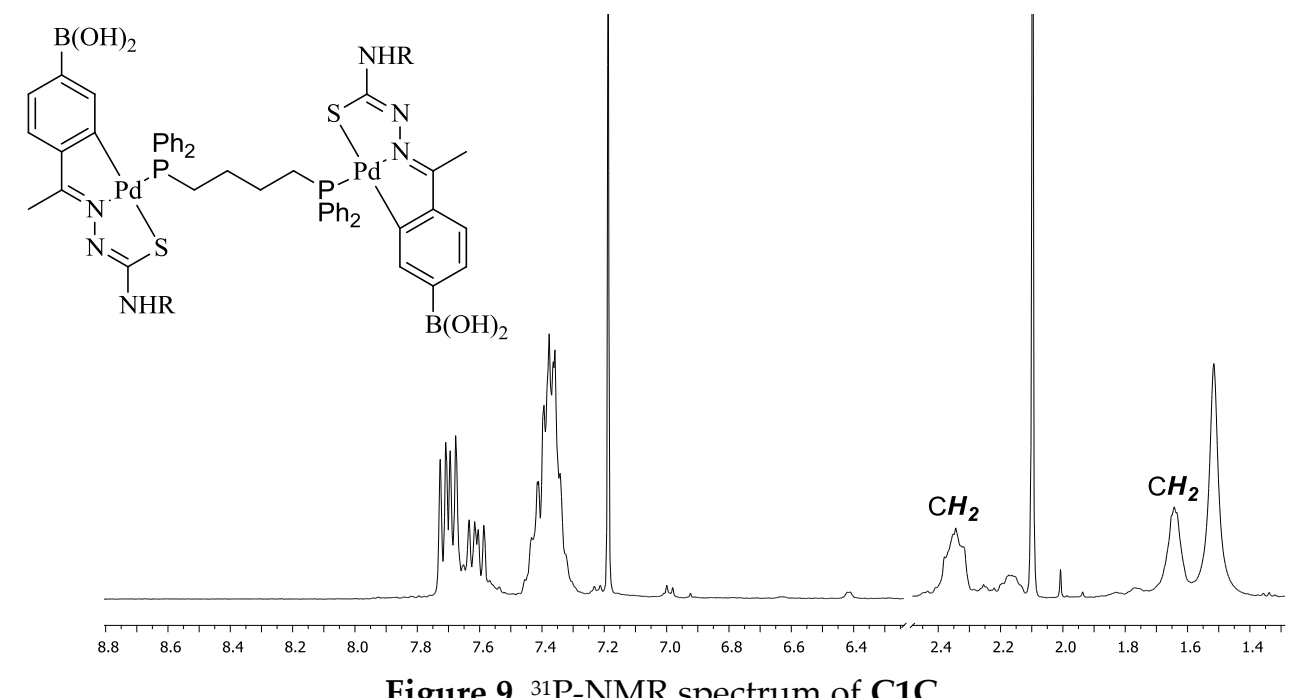

Figure 9. ${ }^{31} \mathrm{P}-\mathrm{NMR}$ spectrum of $\mathrm{C} 1 \mathrm{C}$

The ${ }^{31} \mathrm{P}-\mathrm{NMR}$ spectra showed a singlet $c a .29 \mathrm{ppm}$ in agreement with equivalent ${ }^{31} \mathrm{P}$ nuclei. (Table 4).

Table 4. ${ }^{31} \mathrm{P}-\mathrm{NMR}$ data for the dppb derivatives.

\begin{tabular}{cccc}
\hline Signal & $\mathrm{C} 1 \mathrm{C} / \delta(\mathrm{ppm})$ & $\mathrm{C} 2 \mathrm{C} / \delta(\mathrm{ppm})$ & $\mathrm{C} 3 \mathrm{C} / \delta(\mathrm{ppm})$ \\
\hline $\mathrm{Pd}-\mathrm{PPh}_{2}$ & 28.42 & 28.43 & 29.48 \\
\hline
\end{tabular}

\section{Conclusions}

The synthesis of a series of palladacycles was accomplished, and their reactivity towards different phosphine ligands gave mononuclear and dinuclear structures, as appropriate. 
Acknowledgments: We wish to thank the financial support received from the Xunta de Galicia (Galicia, Spain) under the Grupos de Referencia Competitiva Programme Projects GRC2015/009. F. Reigosa and F. Lucio thank the Spanish Ministry of Education (grant FPU15/07145 and FPU13/05014)

Conflicts of Interest: The authors declare no conflict of interest.

\section{References}

1. Kovala-Demertzi, D.; Galani, A.; Miller, J.R.; Frampton, C.S.; Demertzis, M.A. Synthesis, structure, spectroscopic studies and cytotoxic effect of novel palladium(II) complexes with 2-formylpyridine-4-Nethyl-thiosemicarbazone: Potential antitumour agents. Polyhedron, 2013, 52, 1096, 10.1016/j.poly.2012.06.068.

2. Arancibia, R.; Quintana, C.; Biot, C.; Medina, M.E.; Carrère-Kremer, S.; Kremer, L.; Klahn, A.H. Palladium (II) and platinum (II) complexes containing organometallic thiosemicarbazone ligands: Synthesis, characterization, X-ray structures and antitubercular evaluation. Inorg. Chem. Communications, 2015, 55, 139, 10.1016/j.inoche.2015.03.036.

3. Khany, S.D.; Gut, J.; Rosenthal, P.J.; Chibale, K.; Smith, G.S. Ferrocenylthiosemicarbazones conjugated to a poly(propyleneimine) dendrimer scaffold: Synthesis and in vitro antimalarial activity J. Organomet. Chem., 2011, 696, 3296, 10.1016/j.jorganchem.2011.07.028.

4. Ohff, M.; Ohff, A.; van der Boom, M.E.; Milstein, D. Highly Active Pd(II) PCP-Type Catalysts for the Heck Reaction. J. Am. Chem. Soc., 1997, 119, 11687, 10.1021/ja9729692.

5. Prabhu, R.N.; Ramesh, R. Synthesis and structural characterization of palladium (II) thiosemicarbazone complex: application to the Buchwald-Hartwig amination reaction. Tetrahedron Letters, 2013, 54, 1120.

6. Alacid, E.; Nájera, C. The First Fluoride-Free Hiyama Reaction of Vinylsiloxanes Promoted by Sodium Hydroxide in Water. Adv. Synth. Catal., 2006, 348, 2085, 10.1002/adsc.200600262.

7. Suganthy, P.K.; Prabhu, R.N.; Sridevi, V.S. Palladium(II) thiosemicarbazone complex: Synthesis, structure and application to carbon-oxygen cross-coupling reaction. Inorg. Chem. Communications, 2014, 44, 67, 10.1016/j.inoche.2014.03.002.

8. Vila, J.M.; Pereira, M.T.; Ortigueira, J.M.; Graña, M.; Lata, D.; Suárez, A.; Fernández, J.J.; Fernández, A.; López-Torres, M.; Adams, H. Formation, characterization, and structural studies of novel thiosemicarbazone palladium(II) complexes. Crystal structures of $\left[\left\{\mathrm{Pd}\left[\mathrm{C}_{6} \mathrm{H}_{4} \mathrm{C}(\mathrm{Et})=\mathrm{NN}=\mathrm{C}(\mathrm{S}) \mathrm{NH}_{2}\right]\right\}_{4}\right]$, $\left[\mathrm{Pd}\left\{\mathrm{C}_{6} \mathrm{H}_{4} \mathrm{C}(\mathrm{Et})=\mathrm{NN}=\mathrm{C}(\mathrm{S}) \mathrm{NH}_{2}\right\}\left(\mathrm{PMePh}_{2}\right)\right]$ and $\left[\left\{\mathrm{Pd}\left[\mathrm{C}_{6} \mathrm{H}_{4} \mathrm{C}(\mathrm{Et})=\mathrm{NN}=\mathrm{C}(\mathrm{S}) \mathrm{NH}_{2}\right]\right\}_{2}\left(\mu-\mathrm{Ph}_{2} \mathrm{PCH}_{2} \mathrm{PPh}_{2}\right)\right]$. J. Chem. Soc. Dalton Trans., 1999, 23, 4193, 10.1039/A906276I.

9. Adrio, L.A. Compuestos ciclometalados de Paladio (II): aplicaciones en catálisis. PhD Dissertation, University of Santiago de Compostela, 2006.

10. Bermúdez, B. Compuestos ciclometalados de paladio y platino: reacciones de acoplamiento y catálisis. PhD Dissertation, University of Santiago de Compostela, 2014. 